\title{
INOCULAÇÃO DE Curtobacterium flaccumfaciens pv. flaccumfaciens EM SEMENTES DE FEIJÃO POR MEIO DA TÉCNICA DE CONDICIONAMENTO FISIOLÓGICO ${ }^{1}$
}

\author{
CAROLINA CARDOSO DEUNER ${ }^{2}$, RICARDO MAGELA DE SOUZA ${ }^{3}$, ALESSANDRA KEIKO \\ NAKASONE ISHIDA ${ }^{4}$, ANA BEATRIZ ZACARONI ${ }^{5}$, ÉDILA VILELA DE RESENDE VON PINHO ${ }^{6}$ \\ JOSÉ DA CRUZ MACHADO ${ }^{7}$, JULIANE NICOLODI CAMERA ${ }^{8}$
}

\begin{abstract}
RESUMO - Neste estudo foi testada a técnica de condicionamento fisiológico em meio agarizado para inoculação de Curtobacterium flaccumfaciens pv. flaccumfaciens (Cff) em sementes de feijão. Na primeira etapa, avaliou-se o comportamento das sementes de feijão cultivar Pérola, durante o pré-condicionamento osmótico em substrato agarizado com restrição hídrica. Os tratamentos consistiram em expor, por diferentes períodos de tempo, sementes de feijão desinfestadas a quatro níveis de restrição hídrica do meio $523(-0,55,-0,75,-0,95$ e $-1,15 \mathrm{MPa})$, com o uso de quatro substratos (meio 523, meio $523+\mathrm{KCl}$, meio 523+manitol e meio 523+sacarose). Como testemunha, utilizou-se o meio 523 sem restrição hídrica (-0,55 MPa). Decorridos os respectivos tempos, avaliou-se a percentagem de sementes com protrusão radicular e, posteriormente, o teor de água, a germinação e os padrões enzimáticos das sementes. Na segunda etapa do estudo, avaliou-se o crescimento de quatro isolados de Cff (Cff DF - Feij-2936, Cff PR - 12768, Cff SC Feij-2928 e Cff SP - Feij-2634) em substrato agarizado com restrição hídrica. Os tratamentos da terceira etapa foram definidos com base na primeira etapa, em que o melhor tratamento foi o meio 523 com manitol no potencial hídrico de -0,95 MPa e com 48 horas de exposição das sementes no meio agarizado. Na segunda etapa, verificou-se que o isolado de Cff SC (Feij-2928), proveniente do estado de Santa Catarina, apresentou o melhor crescimento no substrato e no potencial hídrico definido na primeira etapa. Portanto, foi possível a inoculação artificial de sementes de feijão com Cff por meio da técnica de condicionamento fisiológico em substrato agarizado, sem o comprometimento de sua qualidade fisiológica.
\end{abstract}

Termos para indexação: Phaseolus vulgaris L., murcha-de-curtobacterium, restrição hídrica.

\section{INOCULATION OF DRY BEAN SEEDS WITH Curtobacterium flaccumfaciens pv. flaccumfaciens (Cff) USING THE PHYSIOLOGICAL CONDITIONING TECHNIQUE}

ABSTRACT - This study used the physiological conditioning technique in an agar-based medium for Curtobacterium flaccumfaciens pv. flaccumfaciens (Cff) to inoculate dry beans. The seed performance of the Pérola dry bean variety was evaluated after submitting it to physiological

\footnotetext{
${ }^{1}$ Submetido em 10/02/2009. Aceito para publicação em 22/09/2010. Parte da Tese de Doutorado da primeira autora apresentada à UFLA. Financiado pela Fundação de Apoio à Pesquisa de Minas Gerais - FAPEMIG.

${ }^{2}$ Professora Universidade de Passo Fundo, UPF, Faculdade de Agronomia e Medicina Veterinária, C.P. 611, 99052-900, Passo Fundo, RS, carolinadeuner@upf.br;

${ }^{3}$ Professor Universidade Federal de Lavras, UFLA, Departamento de Fitopatologia. C.P. 3037, 37200-000, Lavras, MG.

${ }^{4}$ Pesquisadora Embrapa Amazônia Oriental, C.P. 48, CEP 66095-100, Belém, PA.
}

\footnotetext{
${ }^{5}$ Doutoranda Universidade Federal de Lavras, UFLA, Departamento de Fitopatologia.

${ }^{6}$ Professora Universidade Federal de Lavras, UFLA, Departamento de Agricultura/Setor de Sementes, C.P. 3037, CEP 37200-000, Lavras, MG.

${ }^{7}$ Professor Universidade Federal de Lavras, UFLA, Departamento de Fitopatologia. C.P. 3037, 37200-000, Lavras, MG.

${ }^{8}$ Mestranda da Universidade de Passo Fundo, UPF, Faculdade de Agronomia e Medicina Veterinária.
} 
conditioning in a water restricted agar-based medium. The treatments consisted of exposing dry bean seeds to the bacteria for different time periods at four levels of water restriction in 523 medium ( $-0.55,-0.75,-0.95$ and $-1.15 \mathrm{MPa})$, and four substrates $(523$ medium, 523 medium $+\mathrm{KCl}$, 523 medium+mannitol and 523 medium+sucrose) with an additional control treatment of 523 medium without any osmotic restriction (-0,55 MPa). After each time period, the number of germinated seeds in the medium was evaluated and the water content, germination and seed enzymatic patterns were assessed. In a second study, growth was assessed for four Cff strains (Cff DF - Feij-2936, Cff PR - 12768, Cff SC - Feij-2928 e Cff SP - Feij-2634) in different water restriction 523 media. The treatments in the third phase were defined on the basis of the results of the first stage, where the best combination was mannitol-amended 523 medium set for $-0,95$ MPa water potential and 48 hours exposure to the pathogen. In the second phase, the Cff SC (Feij2928) strain from Santa Catarina state showed the best growth in an agar-based medium and water potential as defined in the first phase. Thus, Cff artificial inoculation in bean seeds was done by using the physiological conditioning technique in an agar-based medium without the occurrence of any detectable changes in the seed physiological quality patterns.

Index terms: Phaseolus vulgaris L., wilt-of-Curtobacterium, water restriction.

\section{INTRODUÇÃO}

Métodos eficazes e confiáveis para a inoculação de sementes são úteis em estudos de detecção e transmissão de patógenos por sementes, comportamento epidemiológico de doenças transmitidas por sementes, determinação da sensibilidade de métodos de detecção, dentre outros (Valarini e Menten, 1991). Apesar disso, é difícil se obter níveis adequados de patógenos em sementes, o que torna necessário o desenvolvimento de métodos que garantam a associação do patógeno com as mesmas, sem, no entanto, provocar perdas significativas na qualidade fisiológica. As técnicas de inoculação de patógenos em sementes, em sua maioria, reduzem consideravelmente o seu poder germinativo (Valarini e Menten, 1991), revelam baixa eficiência na obtenção de índices satisfatórios de transmissibilidade do patógeno para as plântulas e são ineficientes em evidenciar os efeitos do patógeno na semente.

A análise da atividade enzimática é uma ferramenta indicadora da qualidade fisiológica das sementes submetidas ao condicionamento osmótico, pois detecta os eventos deteriorativos iniciais nas sementes por meio da avaliação de enzimas associadas à degradação e oxidação de substâncias de reserva (Spinola et al., 2000). A capacidade de avaliação e a correta interpretação da variação eletroforética nos perfis de proteínas e enzimas podem ser eficientes ferramentas na determinação de mudanças bioquímicas resultantes do processo deteriorativo (Carraro, 1990).

Objetivou-se neste trabalho desenvolver uma técnica eficiente de inoculação de Curtobacterium flaccumfaciens pv. Alaccumfaciens (Hedges) Collins e Jones (Cff) em sementes de feijão, por condicionamento fisiológico, mantendo-se a sua qualidade fisiológica.

\section{MATERIAL E MÉTODOS}

Foram utilizadas amostras de sementes básicas de feijão, cv. Pérola, as quais foram armazenadas em câmara fria e seca $\left(10^{\circ} \mathrm{C}\right.$ e $50 \%$ UR), até a realização dos experimentos.

O teste de germinação foi realizado em rolo de papel com 4 repetições de 50 sementes e o de sanidade em papel filtro, utilizando-se 400 sementes dispostas em recipientes gerbox, previamente desinfestados em hipoclorito de sódio (NaCEO $0,5 \%$ ). Ambos os testes foram realizados segundo os critérios estabelecidos nas Regras para Análise de Sementes (Brasil, 1992). Para a detecção de Cff foi realizado o plaqueamento em meio de cultura CNS (Schaad et al., 2001).

Foram utilizados neste trabalho os isolados Cff DF Feij-2936, Cff PR - 12768, Cff SC - Feij-2928 e Cff SP - Feij-2634, cedidos pelos pequisadores R.P. Leite Jr. (IAPAR) e A.C. Maringoni (UNESP). Todos os isolados foram submetidos ao teste de patogenicidade. 
Primeira etapa: pré-condicionamento de sementes de feijão em substrato agarizado com restrição hídrica

O meio de cultura básico utilizado foi o 523 (Kado e Heskett, 1970) cujo potencial hídrico é de -0,546 MPa. Para calcular as quantidades dos solutos no preparo das soluções, nos diferentes níveis de potencial hídrico $(-0,75$, $-0,95$ e $-1,15 \mathrm{MPa}$ ), utilizou-se o software SPPM (Michel e Radcliffe, 1995). Os tratamentos consistiram em expor sementes de feijão desinfestadas com $\mathrm{NaCEO} 0,5 \%$ por 2 minutos e lavadas três vezes em água destilada esterilizada, a quatro substratos diferentes (meio 523, 523+KCl, $523+$ manitol e $523+$ sacarose), em quatro potenciais de restrição hídrica do meio $523(-0,55,-0,75,-0,95$ e $-1,15$ $\mathrm{MPa}$ ) por períodos de 24, 48, 72, 96 e 120 horas. Foram colocadas 20 sementes por placa de Petri de $9 \mathrm{~cm}$ de diâmetro contendo $40 \mathrm{~mL}$ de meio, sendo cada tratamento composto por 20 placas, totalizando 400 sementes. As placas foram incubadas por diferentes períodos de tempo $(24,48,72,96$ e 120 horas), a $28{ }^{\circ} \mathrm{C}$, sob escuro contínuo. Decorridos os respectivos tempos, avaliou-se o número total de sementes germinadas por placa. As sementes foram consideradas germinadas quando apresentaram sinais da protrusão da radícula $(\geq 0,1 \mathrm{~cm})$. As sementes que não apresentaram protrusão da radícula foram utilizadas para a determinação do teor de água pelo método da estufa, a $105 \pm 3{ }^{\circ} \mathrm{C}$, por 24 horas e parte foi seca até atingir 13\% de teor de água para determinação da germinação, pelo teste em rolo de papel, de acordo com as Regras para Análise de Sementes (Brasil, 1992). Os resultados foram expressos em percentagem para teor de água e plântulas normais para germinação.

As análises eletroforéticas de isoenzimas foram realizadas de acordo com o protocolo de Vieira et al. (2001), nos tratamentos 24 e 120 horas de exposição em todos os substratos e potenciais hídricos, mais testemunha sem condicionamento osmótico. Os sistemas isoenzimáticos avaliados foram: catalase (CAT) e peroxidase (PO). O delineamento experimental foi o de blocos casualizados, com quatro repetições. Os tratamentos referentes à emissão de radículas consistiram em um fator quantitativo (restrição hídrica) em quatro potenciais hídricos do meio $523(-0,55,-0,75,-0,95$ e $-1,15 \mathrm{MPa})$ e um fator qualitativo (substratos) meio 523 , meio $523+\mathrm{KCl}$, meio $523+$ manitol e meio 523+sacarose.

Segunda etapa: crescimento de isolados de $C f f$ em substrato agarizado com restrição hídrica

Os tratamentos foram constituídos por quatro tipos de substratos (meio 523, 523+KCl, 523+manitol e $523+$ sacarose), em quatro potenciais de restrição hídrica do meio $523(-0,55,-0,75,-0,95$ e $-1,15 \mathrm{MPa})$. Para o estudo do crescimento bacteriano em meio 523 com diferentes potenciais de restrição hídrica, foram utilizados os quatro isolados de Cff descritos anteriormente. Esse ensaio foi realizado em blocos casualizados, com quatro repetições por tratamento. Em cada placa, foram adicionados $40 \mathrm{~mL}$ de substrato e, após a solidificação, $100 \mu \mathrm{L}$ de suspensão bacteriana foram plaqueados e espalhados com uma alça de Drigalski. As placas foram incubadas em BOD, a $28^{\circ} \mathrm{C}$, por 72 horas e em seguida observou-se as características típicas das colônias e contou-se o número de colônias em todas as placas. $\mathrm{O}$ delineamento experimental foi o de blocos casualizados. Os tratamentos seguiram o arranjo fatorial com um fator quantitativo, quatro potenciais hídricos do meio $523(-0,55,-0,75,-0,95$ e $-1,15 \mathrm{MPa})$ e dois fatores qualitativos: tipo de substratos (meio $523,523+\mathrm{KCl}$, $523+$ manitol e $523+$ sacarose) e diluição $\left(10^{-4}\right)$, sendo a testemunha, o meio 523 sem restrição hídrica (-0,55 MPa).

Terceira etapa: uso de condicionamento fisiológico na inoculação de $\boldsymbol{C f f}$ em sementes de feijão

Os tratamentos dessa etapa foram definidos com base na primeira etapa. Foram utilizados o melhor substrato e o potencial de restrição hídrica no pré-condicionamento das sementes de feijão, ou seja, o meio 523 com manitol no potencial hídrico de $-0,95 \mathrm{MPa}$. $\mathrm{O}$ isolado escolhido foi o Cff SC - Feij-2928, proveniente do estado de Santa Catarina, por apresentar melhor crescimento no substrato e potencial hídrico definidos na primeira etapa. Para determinar o tempo de exposição das sementes o isolado de Cff SC Feij-2928, foi cultivado em meio 523 líquido por 48 horas em BOD, a $28{ }^{\circ} \mathrm{C}$. Em seguida, $100 \mu \mathrm{L}$ da suspensão bacteriana do isolado foram plaqueados em placas de Petri de $9 \mathrm{~cm}$ de diâmetro, contendo $20 \mathrm{~mL}$ dos substratos. Os tratamentos foram constituídos por meio 523, 523+manitol e $523+$ manitol $+C f f$. As placas foram incubadas em BOD, a $28{ }^{\circ} \mathrm{C}$, por 72 horas. Decorrido o período de incubação, procedeu-se à inoculação, em condições assépticas, das sementes desinfestadas, colocando-se 20 sementes por placa. As sementes permaneceram em contato com o inóculo por 24, 48, 72, 96 e 120 horas, em BOD, a $28{ }^{\circ} \mathrm{C}$. Ao fim do período de exposição, as sementes foram avaliadas quanto ao teor de água e as restantes secadas até 13\% de umidade, para posteriores avaliações. O teor de água e a germinação das sementes foram determinados após cada período de exposição das sementes ao substrato agarizado pelo método da estufa, a $105 \pm 3{ }^{\circ} \mathrm{C}$, por 24 horas e pelo teste em rolo de papel (Brasil, 1992). Para o teor de água os resultados foram expressos em percentagem e para germinação em percentagem de plântulas normais. 


\section{RESULTADOS E DISCUSSÃO}

\section{Qualidade das sementes de feijão}

A germinação inicial das sementes de feijão cultivar Pérola foi de $94 \%$. No teste de sanidade, constatou-se a presença dos seguintes gêneros de fungos: Aspergillus spp. (1,5\%), Colletotrichum spp. (1,25\%), Fusarium spp. (2\%) e Penicillium spp. (1,75\%). Com relação a $C f f$, não foi encontrada a presença dessa bactéria por meio do plaqueamento do extrato das sementes em meio de cultura CNS (Schaad et al., 2001).

Primeira etapa: pré-condicionamento de sementes de feijão em substrato agarizado com restrição hídrica

Nesse ensaio foram observados menores percentuais de protrusão radicular das sementes de feijão durante o précondicionamento osmótico em tratamentos com maiores potenciais hídricos, independentes do substrato. Nos potenciais mais negativos, as sementes de feijão tenderam a diminuir o processo germinativo no substrato, enquanto que, nos tratamentos com potencias menores, a germinação iniciou-se mais cedo (Tabela 1). Esses resultados estão de acordo com os de outros autores (Carvalho, 1999; Coutinho, 2000), nos quais a velocidade de absorção de água pelas sementes diminui à medida que o potencial hídrico do meio externo torna-se mais negativo, aumentando, conseqüentemente, o período necessário para que ocorra a emissão da radícula.

TABELA 1. Média da percentagem das sementes de feijão germinadas durante o pré-condicionamento osmótico em meio 523 contendo cloreto de potássio $(\mathrm{KCl})$, manitol e sacarose, nos diferentes tempos de exposição $(24,48,72,96$ e 120 horas).

\begin{tabular}{lcccccc}
\hline \multirow{2}{*}{ Substrato } & \multirow{2}{*}{$\Psi(\mathrm{MPa})$} & \multicolumn{5}{c}{ Tempo } \\
\cline { 2 - 6 } & & 24 horas & 48 horas & 72 horas & 96 horas & 120 horas \\
\hline Meio 523 & $-0,55$ & $0 \mathrm{a}^{1}$ & $93 \mathrm{a}$ & $95 \mathrm{a}$ & $98 \mathrm{a}$ & $98 \mathrm{a}$ \\
Meio 523+KCl & $-0,75$ & $0 \mathrm{a}$ & $4 \mathrm{~b}$ & $20 \mathrm{~b}$ & $69 \mathrm{~b}$ & $33 \mathrm{~b}$ \\
Meio 523+KCl & $-0,95$ & $0 \mathrm{a}$ & $0 \mathrm{c}$ & $12 \mathrm{c}$ & $5 \mathrm{c}$ & $9 \mathrm{c}$ \\
Meio 523+KCl & $-1,15$ & $0 \mathrm{a}$ & $0 \mathrm{c}$ & $0 \mathrm{c}$ & $0 \mathrm{~d}$ & $1 \mathrm{~d}$ \\
Meio 523+Man & $-0,75$ & $0 \mathrm{a}$ & $0 \mathrm{c}$ & $4 \mathrm{c}$ & $10 \mathrm{c}$ & $28 \mathrm{~b}$ \\
Meio 523+Man & $-0,95$ & $0 \mathrm{a}$ & $0 \mathrm{c}$ & $1 \mathrm{c}$ & $4 \mathrm{c}$ & $9 \mathrm{c}$ \\
Meio 523+Man & $-1,15$ & $0 \mathrm{a}$ & $0 \mathrm{c}$ & $0 \mathrm{c}$ & $0 \mathrm{~d}$ & $4 \mathrm{~d}$ \\
Meio 523+Sac & $-0,75$ & $0 \mathrm{a}$ & $0 \mathrm{c}$ & $0 \mathrm{c}$ & $0 \mathrm{~d}$ & $3 \mathrm{~d}$ \\
Meio 523+Sac & $-0,95$ & $0 \mathrm{a}$ & $0 \mathrm{c}$ & $0 \mathrm{c}$ & $0 \mathrm{~d}$ & $1 \mathrm{~d}$ \\
Meio 523+Sac & $-1,15$ & $0 \mathrm{a}$ & $0 \mathrm{c}$ & $0 \mathrm{c}$ & $0 \mathrm{~d}$ & $1 \mathrm{~d}$ \\
\hline
\end{tabular}

${ }^{1}$ Médias seguidas pela mesma letra na coluna não diferem estatisticamente entre si, em $5 \%$ de probabilidade, pelo teste de Duncan.

Todos os três substratos testados na protrusão da radícula foram estatisticamente superiores à testemunha para a maioria dos tempos, exceto para o tempo de 24 horas. Na maioria dos tratamentos, houve redução considerável da germinação das sementes de feijão no pré-condicionamento, ou seja, os solutos não permitiram a absorção ideal de água para que ocorresse o processo de protrusão radicular. No tratamento testemunha, meio 523 (-0,55 MPa), o início da emissão da radícula ocorreu com 48 horas de exposição das sementes e, após 96 horas, $98 \%$ das sementes estavam germinadas.

No tratamento meio $523+\mathrm{KCl}$, foram observadas as maiores percentagens de germinação das sementes quando comparado ao meio $523+$ manitol e ao meio $523+$ sacarose. Para o menor potencial hídrico, - 0,75 $\mathrm{MPa}$, o início da emissão da radícula deu-se com 48 horas de exposição da semente ao meio e atingiu 4\% de sementes germinadas. Para -0,95 MPa de potencial, a emissão da radícula iniciouse a 72 horas de exposição, apresentando $12 \%$ de sementes germinadas. Para o maior potencial hídrico, o de $-1,15$ $\mathrm{MPa}$, a germinação no meio iniciou-se com 120 horas, apresentando média de sementes germinadas de $1 \%$.

Para o tratamento meio 523+manitol, as sementes nos potenciais $-0,75$ e $-0,95 \mathrm{MPa}$ iniciaram o processo germinativo a partir de 72 horas, tendo as percentagens de sementes germinadas de $4 \%$ e $1 \%$, respectivamente. 
Com relação ao maior potencial hídrico, a germinação das sementes iniciou-se com 120 horas, apresentando 4\% de sementes germinadas.

O tratamento com o meio 523+sacarose apresentou melhor desempenho em controlar a emissão de radícula pela semente no substrato agarizado. A germinação de sementes para esse tratamento iniciou-se com 120 horas, para os potenciais hídricos, $-0,75,-0,95$ e $-1,15 \mathrm{MPa}$, apresentando $3 \%, 1 \%$ e $1 \%$ de sementes germinadas, respectivamente. Para o substrato meio $523+$ sacarose, nos períodos compreendidos entre 24 e 96 horas, não houve emissão da radícula nas sementes. Isso ocorreu, provavelmente, porque a restrição hídrica do substrato permite que as sementes absorvam água até um determinado nível, em que todos os processos preparatórios para a germinação ocorram sem atingir a fase de elongamento celular e, conseqüentemente, a emissão da radícula (Bradford, 1986).

As diferenças verificadas entre os solutos utilizados com relação à eficiência em inibir ou retardar a germinação das sementes podem estar relacionadas à toxidez dos solutos e diferenças de potencial hídrico de equilíbrio entre a semente e o meio externo. Segundo Bradford (1986), essas diferenças podem variar amplamente em função das características das sementes de cada espécie e/ou cultivar e, possivelmente, entre lotes de uma mesma cultivar. Portanto, os resultados obtidos neste estudo foram semelhantes aos obtidos por Campos e Assunção (1990), que constataram redução na germinação de sementes de arroz e feijão à medida que decresceram os níveis de potencial hídrico das soluções preparadas com manitol, PEG 1540, PEG 6.000, $\mathrm{NaCl}$ e $\mathrm{Na}_{2} \mathrm{SO}_{4}$

\section{Teor de água nas sementes}

O teor de água atingido pelas sementes de feijão variou em função do tempo, do substrato e do potencial de restrição hídrica, porém, ele cresceu com o aumento do tempo de exposição das sementes ao substrato. Sementes da testemunha, meio 523 sem restrição hídrica, apresentaram maiores teores de água, independente dos substratos, diferindo estatisticamente dos demais tratamentos (Figura 1). Sementes que apresentam maior teor de água sofrem maiores efeitos deletérios do estresse, devido à intensificação da sua atividade metabólica. Essas sementes apresentam menor integridade do seu sistema de membranas e/ou seletividade, permitindo a entrada de água mais rapidamente nas células (Santos et al., 2004).

\section{CLORETO DE POTÁSSIO}

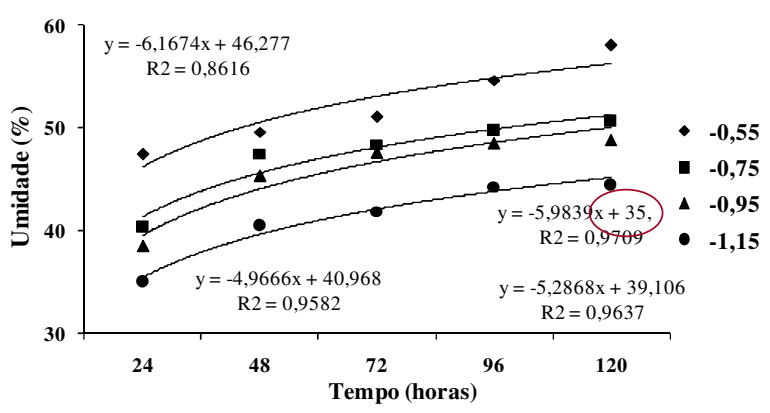

\section{MANITOL}

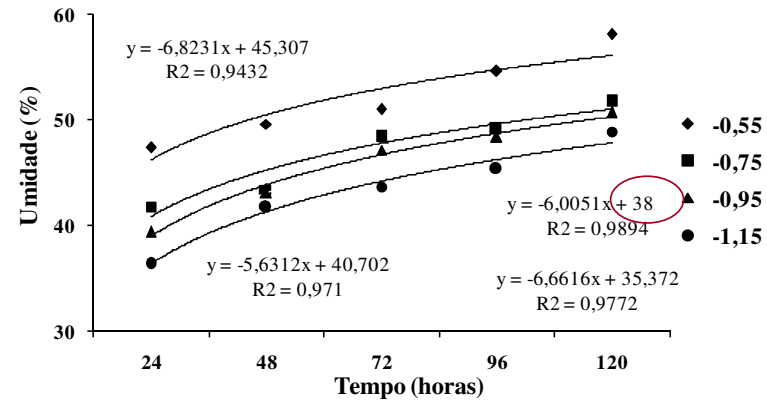

SACAROSE

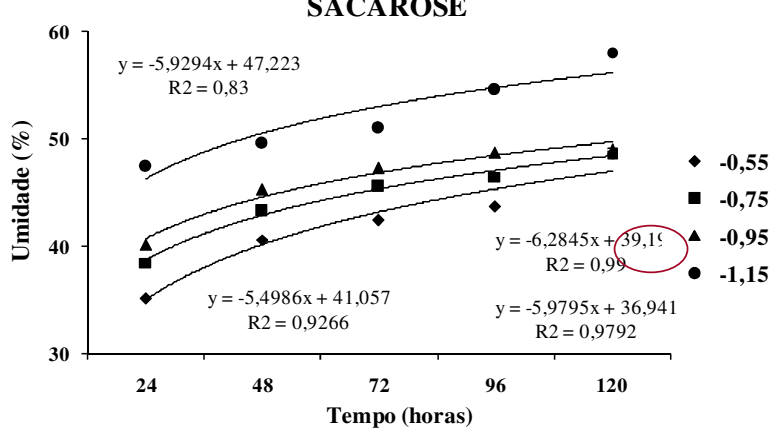

FIGURA 1. Análise de regressão para teor de água médio nas sementes de feijão após o pré-condicionamento osmótico em meio 523 contendo cloreto de potássio $(\mathrm{KCl})$, manitol e sacarose, nos diferentes tempos de exposição (24, 48, 72, 96 e 120 horas). 
À medida que se aumentou o potencial hídrico, independente do tempo e do substrato, existiu uma tendência em reduzir a absorção de água. Sementes expostas por 24 e 120 horas, independente do substrato e do potencial hídrico, apresentaram menores e maiores teores de água, respectivamente. Para os substratos contendo manitol e sacarose no tempo de 120 horas, não houve diferença estatística entre os potenciais $-0,75$ e $-0,95 \mathrm{MPa}$, o que não aconteceu para os demais tempos, em que todos os tratamentos foram estatisticamente diferentes entre si. Esses resultados concordam com os dados encontrados por Souza et al. (1996), ao verificarem em sementes de calopogônio que, no final do período de embebição, os lotes que exibiram maiores proporções de sementes intumescidas eram os lotes de menor qualidade fisiológica.

\section{Teste de germinação das sementes}

Após o pré-condicionamento nos diferentes substratos e potenciais hídricos, sementes de feijão que não apresentaram protrusão radicular foram submetidas ao teste de germinação em rolo de papel. Todos os três substratos testados nesse ensaio, independente do potencial hídrico, demonstraram ser estatisticamente superiores à testemunha, na qual foi observada redução na germinação das sementes à medida que se aumentou o tempo de exposição (Tabela 2), apresentando germinação em torno de $50 \%$, no tempo de 120 horas de exposição das mesmas.

TABELA 2. Germinação média das sementes de feijão após o pré-condicionamento osmótico em meio 523 contendo cloreto de potássio $(\mathrm{KCl})$, manitol e sacarose, nos diferentes tempos de exposição $(24,48,72,96$ e 120 horas).

\begin{tabular}{lcccccc}
\hline \multirow{2}{*}{ Substrato } & \multirow{2}{*}{$\Psi(\mathrm{MPa})$} & \multicolumn{5}{c}{ Tempo } \\
\cline { 2 - 6 } & & 24 horas & 48 horas & 72 horas & 96 horas & 120 horas \\
\hline Meio 523 & $-0,55$ & $91 \mathrm{a}$ & $70 \mathrm{~d}$ & $61 \mathrm{~d}$ & $58 \mathrm{~d}$ & $51 \mathrm{~d}$ \\
Meio 523+KCl & $-0,75$ & $92 \mathrm{a}$ & $82 \mathrm{~b}$ & $73 \mathrm{~b}$ & $70 \mathrm{~b}$ & $68 \mathrm{~b}$ \\
Meio 523+KCl & $-0,95$ & $91 \mathrm{a}$ & $84 \mathrm{a}$ & $75 \mathrm{a}$ & $73 \mathrm{a}$ & $70 \mathrm{a}$ \\
Meio 523+KCl & $-1,15$ & $88 \mathrm{~b}$ & $80 \mathrm{c}$ & $71 \mathrm{c}$ & $68 \mathrm{c}$ & $65 \mathrm{c}$ \\
Meio 523+Man & $-0,75$ & $92 \mathrm{a}$ & $86 \mathrm{~b}$ & $79 \mathrm{~b}$ & $69 \mathrm{~b}$ & $65 \mathrm{~b}$ \\
Meio 523+Man & $-0,95$ & $92 \mathrm{a}$ & $88 \mathrm{a}$ & $85 \mathrm{a}$ & $82 \mathrm{a}$ & $77 \mathrm{a}$ \\
Meio 523+Man & $-1,15$ & $80 \mathrm{~b}$ & $74 \mathrm{c}$ & $65 \mathrm{c}$ & $65 \mathrm{c}$ & $60 \mathrm{c}$ \\
Meio 523+Sac & $-0,75$ & $91 \mathrm{a}$ & $85 \mathrm{a}$ & $77 \mathrm{a}$ & $74 \mathrm{a}$ & $70 \mathrm{a}$ \\
Meio 523+Sac & $-0,95$ & $91 \mathrm{a}$ & $85 \mathrm{a}$ & $78 \mathrm{a}$ & $75 \mathrm{a}$ & $70 \mathrm{a}$ \\
Meio 523+Sac & $-1,15$ & $79 \mathrm{~b}$ & $71 \mathrm{~b}$ & $65 \mathrm{~b}$ & $63 \mathrm{~b}$ & $58 \mathrm{~b}$ \\
\hline
\end{tabular}

${ }^{1}$ Médias seguidas pela mesma letra na coluna não diferem estatisticamente entre si, em $5 \%$ de probabilidade, pelo teste de Duncan.

Para o tempo de 24 horas, os substratos contendo cloreto de potássio e manitol se comportaram de maneira semelhante nos potenciais hídricos de $-0,75$ e $-0,95 \mathrm{MPa}$ não diferirndo estatisticamente entre si. Os valores de germinação das sementes desses tratamentos foram de $92 \%$ e $91 \%, 92 \%$ e $92 \%$, respectivamente. Para o substrato composto por sacarose não houve diferença estatística na germinação das sementes submetidas aos potencias $-0,75$ e - $0,95 \mathrm{MPa}$, em nenhum dos tempos. O potencial de -1,15 MPa, em todos os tempos e substratos, demonstrou ser, dentre os potenciais testados, o que mais reduziu a germinação. Em estudos com sementes de soja, Braccini et al. (1996) constataram que potenciais hídricos mais negativos, induzidos por soluções osmóticas de $\mathrm{NaCl}$ e manitol reduziram a germinação de sementes. A diferença de desempenho observada entre sementes submetidas ou não ao pré-condicionamento osmótico em meio agarizado se deve ao fato de que são iniciados vários processos como mobilização das reservas, ativação e síntese-de-novo de várias enzimas, síntese de DNA e RNA, produção de ATP, além de reparo de danos no sistema de membranas (Bradford, 1986). Além disso, a qualidade fisiológica das sementes após o condicionamento osmótico dependerá da quantidade de água absorvida durante esse processo. Quanto maior a quantidade de água perdida durante o processo de secagem, menores serão os percentuais de germinação. Portanto, é importante que, nos trabalhos que envolvam a inoculação artificial de sementes, os tratamentos proporcionem baixa germinação durante o processo de inoculação, por meio do pré-condicionamento fisiológico em meio agarizado e que, após esse processo, a semente esteja fisiologicamente viável e associada ao patógeno. 
Sistemas enzimáticos das sementes

A qualidade fisiológica das sementes após o condicionamento osmótico foi acompanhada pelas alterações nos padrões isoenzimáticos específicos, empregando-se a técnica de eletroforese.

A enzima catalase, independente do restritor hídrico $(\mathrm{KCl}$, manitol e Sacarose) e do potencial hídrico $(-0,75$, $-0,95$ e -1,15 MPa), apresentou maior atividade no tempo de 120 horas de exposição das sementes, ao contrário do que se observou para os demais tratamentos (Figura 2A, 2B, 2C). Os dados obtidos neste trabalho concordam com os de Bailly et al. (2000) que, ao analisar sementes de girassol, observaram associação do condicionamento osmótico à maior atividade da catalase, tendo a germinação das sementes sido reduzida com o aumento da atividade dessa enzima, sugerindo que ela não foi capaz de realizar a desintoxicação de $\mathrm{O}_{2}^{-}$e $\mathrm{H}_{2} \mathrm{O}_{2}$ (Bailly et al., 2000). Em sementes de soja Sung e Chiu (1995), correlacionaram a queda na viabilidade de sementes envelhecidas natural ou artificialmente com alterações nas atividades das enzimas do sistema antioxidante.

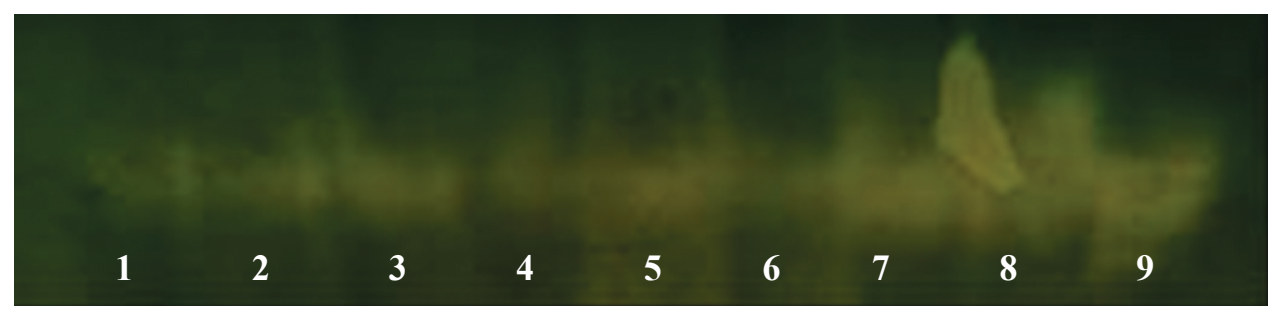

* Sementes sem condicionamento osmótico

FIGURA 2A .Zimograma referente à atividade da enzima catalase em sementes de feijão (1) *Testemunha, (2) meio 523 $24 \mathrm{~h},(3)$ meio 523+KCl 0,75 MPa $24 \mathrm{~h},(4)$ meio 523+KCl 0,95 MPa 24 h, (5) meio 523+KCl 1,15 MPa 24 h, (6) meio 523120 h, (7) meio 523+KCl 0,75 MPa 120 h*, (8) meio 523+KCl 0,95 MPa 120 h*, (9) meio 523+KCl 1,15 MPa $120 \mathrm{~h}$.

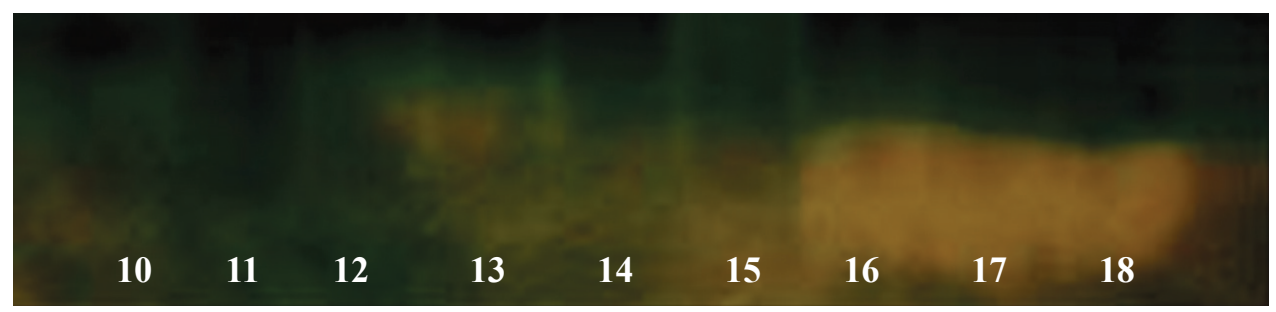

* Sementes sem condicionamento osmótico

FIGURA 2B. (10) *Testemunha, (11) meio 52324 h, (12) meio 523+man 0,75 MPa 24 h, (13) meio 523+man 0,95 MPa 24 h, (14) meio 523+man 1,15 MPa 24 h, (15) meio 523120 h, (16) meio 523+man 0,75 MPa 120 h*, (17) meio 523+man 0,95 MPa 120 h* e (18) meio 523+man 1,15 MPa 120 h*.

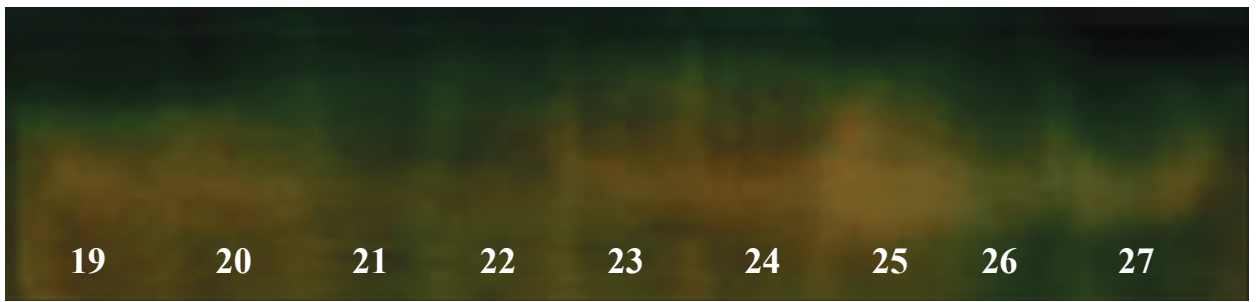

* Sementes sem condicionamento osmótico

FIGURA 2C. (19) *Testemunha, (20) meio 52324 h, (21) meio 523+sac 0,75 MPa 24 h, (22) meio $523+$ sac 0,95 MPa 24 h, (23) meio 523+sac 1,15 MPa 24 h, (24) meio 523120 h, (25) meio 523+sac 0,75 MPa 120 h*, (26) meio 523+sac $0,95 \mathrm{MPa} 120 \mathrm{~h} *$ e (27) meio 523+sac 1,15 MPa $120 \mathrm{~h} *$ 
Para enzima peroxidase, observou-se que, no caso dos restritores hídricos manitol (Figura 3B) e sacarose (Figura 3C), houve aumento de atividade nos potenciais hídricos $(-0,75,-0,95$ e $-1,15 \mathrm{MPa})$ no tempo de exposição de 120 horas, o que não ocorreu com o restritor $\mathrm{KCl}$ (Figura 3A).
Essa enzima é removedora de peróxido e a diminuição da sua atividade pode tornar a semente mais sensível aos efeitos de $\mathrm{O}_{2}$ e radicais livres sobre ácidos graxos insaturados de membrana, o que provoca a degeneração de suas membranas e parece interferir na germinação e vigor das sementes.

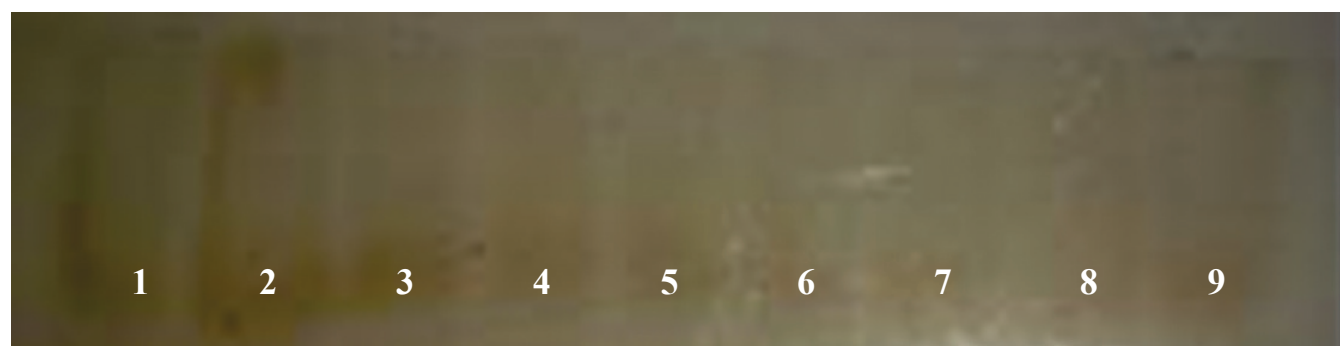

* Sementes sem condicionamento osmótico

FIGURA 3A. Zimograma referente à atividade da enzima peroxidase em sementes de feijão (1) *Testemunha, (2) meio 52324 h, (3) meio 523+KCl 0,75 MPa 24 h, (4) meio 523+KCl 0,95 MPa 24 h, (5) meio 523+KCl 1,15 MPa 24 h, (6) meio 523120 h, (7) meio 523+KCl 0,75 MPa 120 h, (8) meio 523+KCl 0,95 MPa 120 h e (9) meio $523+$ KCl 1,15 MPa 120 h*.

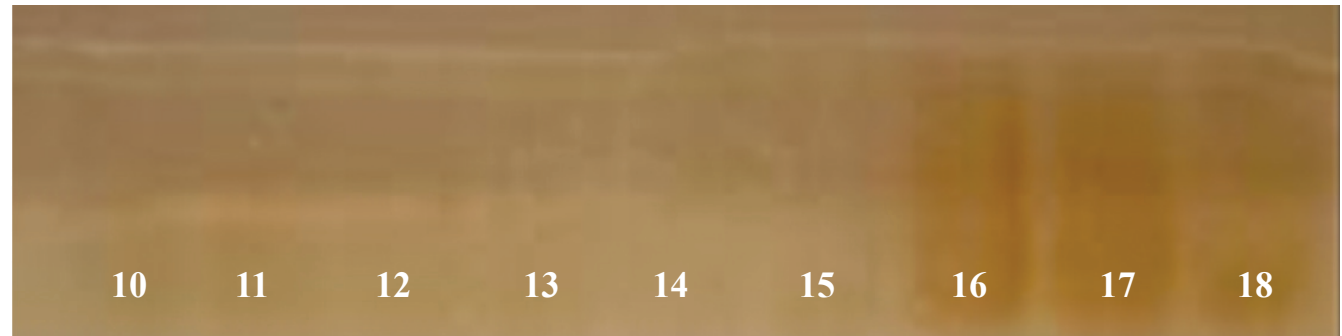

* Sementes sem condicionamento osmótico

FIGURA 3B. (10) *Testemunha, (11) meio $52324 \mathrm{~h}$, (12) meio 523+man 0,75 24 h, (13) meio 523+man 0,95 MPa 24 h, (14) meio 523+man 1,15 MPa 24 h, (15) meio 523120 h, (16) meio 523+man 0,75 MPa 120 h*, (17) meio 523+man 0,95 MPa $120 \mathrm{~h} *$ e (18) meio 523+man 1,15 MPa $120 \mathrm{~h} *$

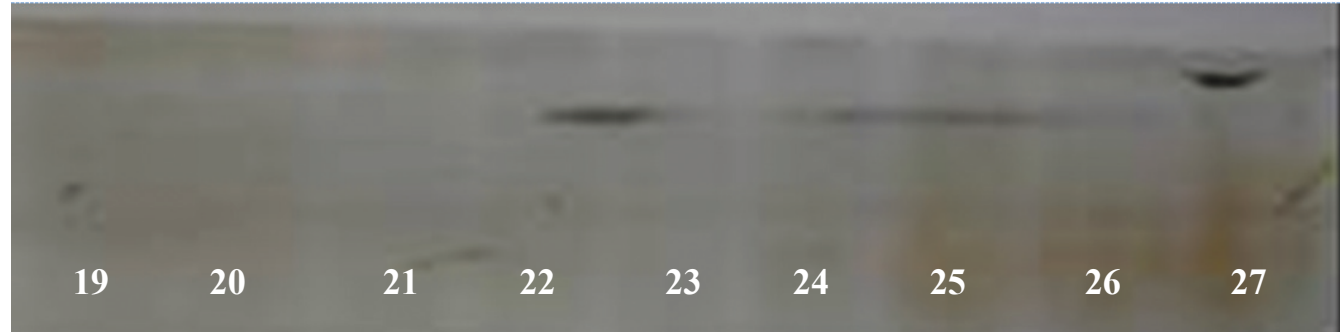

* Sementes sem condicionamento osmótico

FIGURA 3C. (19) *Testemunha, (20) meio 52324 h, (21) meio 523+sac 0,75 MPa 24 h, (22) meio 523+sac 0,95MPa $24 \mathrm{~h}$, (23) meio 523+sac 1,15 MPa 24 h, (24) meio 523120 h, (25) meio 523+sac 0,75 MPa 120 h*, (26) meio 523+sac 0,95 MPa 120 h* e (27) meio 523+sac 1,15 MPa 120 h*.

Como o aumento da atividade de peroxidase está associado às sementes deterioradas, esses resultados enzimáticos são comparáveis à germinação e concordam com os dados de germinação, em que, à medida que se aumentou o tempo de exposição e o potencial de restrição hídrica, a germinação foi reduzida e a atividade da 
referida enzima aumentada. Constatou-se que, na maioria deles, ocorreu decréscimo nas atividades dessas enzimas, concomitante ao envelhecimento, confirmandoa ineficiência do sistema de proteção antioxidante das sementes como causa de perda de vigor (Faria et al., 2003).

Segunda etapa: crescimento de isolados de Cff $\mathrm{em}$ substrato agarizado com restrição hídrica

Com relação às características morfológicas, foi possível verificar que em todos os substratos, independente do potencial hídrico, a morfologia típica das colônias de Cff foi mantida. As colônias apresentavam formato circular, bordos lisos, aspecto brilhante, levemente convexo, com coloração variando de amarela a laranja, conforme as características descritas para o gênero (Romeiro, 2005). A cor típica das colônias de alguns patógenos pode ou não ser influenciada pelos solutos osmóticos nos diferentes potenciais hídricos, concordando com os resultados obtidos nesse ensaio, em que a cor original de cada isolado de $C f f$ não foi alterada.

Quanto ao tamanho das colônias, observou-se relação entre diâmetro da colônia e potenciais hídricos, ou seja, à medida que se diminuiu o potencial hídrico do substrato, o diâmetro das colônias também diminuiu. Esse mesmo comportamento foi verificado por Kobayasti (2002) com a bactéria Xanthomonas axonopodis pv. phaseoli, que apresentou redução no tamanho da colônia, provavelmente devido ao potencial hídrico do meio e à alta concentração de manitol, uma vez que este patógeno não utiliza manitol como fonte de carbono, assim comO para a maioria dos patógenos (Halfeld-Vieira e Souza, 2000).

Para número de colônias, não houve diferença estatística entre os quatro isolados nos diferentes substratos e potencial hídricos (Tabela 3). Esses dados concordam com aqueles encontrados por Barbosa (2007), em seu estudo de inoculação artificial de sementes de algodão com a bactéria $X$. axonopodis pv. malvacearum. Os efeitos combinados da permeabilidade seletiva da membrana ou toxidez de solutos, tanto internamente quanto externamente à membrana celular, provavelmente respondem, em grande parte, pelo crescimento diferenciado de patógenos em vários solutos osmóticos. $\mathrm{O}$ crescimento desses patógenos em meios de cultura ajustados osmoticamente com diferentes potenciais hídricos é variável para cada espécie.

TABELA 3. Número médio das colônias de $C f f$ com 72 horas de idade em meio 523 contendo cloreto de potássio, manitol e sacarose, nos diferentes potenciais hídricos $(-0,55,-0,75,-0,95$ e -1,15 MPa).

\begin{tabular}{lccccc}
\hline \multirow{2}{*}{ Substrato } & \multirow{2}{*}{$\Psi(\mathrm{MPa})$} & \multicolumn{3}{c}{ Isolados } \\
\cline { 3 - 6 } & & CffDF & CffPR & CffSC & CffSP \\
\hline Meio 523 & $-0,55$ & $55,87 \mathrm{a}^{1}$ & $56,33 \mathrm{a}$ & $67,18 \mathrm{a}$ & $60,37 \mathrm{a}$ \\
Meio 523+KCl & $-0,75$ & $55,33 \mathrm{a}$ & $55,87 \mathrm{a}$ & $65,43 \mathrm{a}$ & $60,59 \mathrm{a}$ \\
Meio 523+KCl & $-0,95$ & $54,45 \mathrm{a}$ & $55,45 \mathrm{a}$ & $66,93 \mathrm{a}$ & $59,40 \mathrm{a}$ \\
Meio 523+KCl & $-1,15$ & $55,11 \mathrm{a}$ & $54,67 \mathrm{a}$ & $65,23 \mathrm{a}$ & $59,18 \mathrm{a}$ \\
Meio 523+Man & $-0,75$ & $54,75 \mathrm{a}$ & $54,56 \mathrm{a}$ & $64,18 \mathrm{a}$ & $61,12 \mathrm{a}$ \\
Meio 523+Man & $-0,95$ & $55,93 \mathrm{a}$ & $56,00 \mathrm{a}$ & $67,12 \mathrm{a}$ & $58,98 \mathrm{a}$ \\
Meio 523+Man & $-1,15$ & $56,72 \mathrm{a}$ & $56,25 \mathrm{a}$ & $65,00 \mathrm{a}$ & $60,18 \mathrm{a}$ \\
Meio 523+Sac & $-0,75$ & $54,22 \mathrm{a}$ & $57,11 \mathrm{a}$ & $65,32 \mathrm{a}$ & $60,98 \mathrm{a}$ \\
Meio 523+Sac & $-0,95$ & $54,45 \mathrm{a}$ & $56,23 \mathrm{a}$ & $64,99 \mathrm{a}$ & $57,12 \mathrm{a}$ \\
Meio 523+Sac & $-1,15$ & $53,98 \mathrm{a}$ & $55,12 \mathrm{a}$ & $64,43 \mathrm{a}$ & $59,83 \mathrm{a}$
\end{tabular}

${ }^{1}$ Médias seguidas pela mesma letra na coluna não diferem estatisticamente entre si, em $5 \%$ de probabilidade, pelo teste de Duncan.

Tomando por base os resultados acima descritos quanto ao substrato, o meio contendo manitol propiciou baixa germinação das sementes durante o précondicionamento osmótico, boa germinação das sementes pré-condicionadas e menor número de fungos e bactérias saprófitas nas placas, explicado pelo fato de muitos microrganismos não utilizarem manitol como fonte de carbono ao contrário da sacarose, largamente utilizada. O potencial hídrico de $-0,95 \mathrm{MPa}$, dentre os vários potenciais hídricos no substrato com manitol, foi o que propiciou 
maior germinação das sementes pré-condicionadas, uma das menores absorções de água e os melhores resultados enzimáticos. O isolado Cff SC (Feij-2928) apresentou o maior número de colônias crescidas nos diferentes substratos e potenciais hídricos, entretanto não houve diferença estatística entre os isolados nos diferentes substratos e potenciais hídricos. Esse isolado não teve seu crescimento reduzido pelo uso do manitol e apresentou alta virulência quando inoculado em plantas de feijoeiro. Por isso, foram escolhidos o substrato meio 523+manitol, no potencial hídrico de $-0,95 \mathrm{MPa}$ e o isolado Cff SC (Feij-2928) para a terceira etapa do trabalho.

Terceira etapa: uso de condicionamento fisiológico na inoculação de $C f f$ SC (Feij-2928) em sementes de feijão

Teor de água nas sementes após inoculação artificial

$\mathrm{O}$ teor de água atingido pelas sementes nos diferentes tratamentos variou significativamente, em função da presença e da ausência da bactéria Cff SC (Feij-2928). As sementes expostas ao tratamento meio 523+manitol sem bactéria foram as que apresentaram o menor teor de água, seguido pelo tratamento meio 523+manitol com bactéria (Tabela 4). As sementes expostas às colônias da bactéria atingiram maior teor de água em todos os tempos, quando comparadas às sementes não inoculadas. Essa diferença, provavelmente, ocorreu devido à presença das colônias da bactéria em atividade que, pelo metabolismo dos açúcares presentes no substrato, pode ter acarretado aumento do potencial hídrico do ambiente de hidratação das sementes, proporcionando maior disponibilidade de água para a germinação das mesmas (Carvalho, 1999). As sementes do meio 523 sem restrição hídrica, ou seja, a testemunha foi estatisticamente superior aos demais tratamentos, em todos os tempos, com relação à absorção de água.

TABELA 4. Teor de água médio das sementes de feijão inoculadas artificialmente com $C f f$ SC (Feij-2928) em meio 523 contendo manitol, no potencial de restrição hídrica de -0,95 MPa.

\begin{tabular}{lccccc}
\hline Tratamentos & 24 horas & 48 horas & 72 horas & 96 horas & 120 horas \\
\hline Meio 523 & $46 \mathrm{a}^{1}$ & $49 \mathrm{a}$ & $58 \mathrm{a}$ & $55 \mathrm{a}$ & $57 \mathrm{a}$ \\
Meio 523+ manitol & $39 \mathrm{c}$ & $44 \mathrm{c}$ & $46 \mathrm{c}$ & $48 \mathrm{c}$ & $49 \mathrm{c}$ \\
Meio 523+ manitol + Cff & $42 \mathrm{~b}$ & $46 \mathrm{~b}$ & $49 \mathrm{~b}$ & $51 \mathrm{~b}$ & $53 \mathrm{~b}$ \\
\hline
\end{tabular}

${ }^{1}$ Médias seguidas pela mesma letra na coluna não diferem estatisticamente entre si, em $5 \%$ de probabilidade, pelo teste de Duncan.

Teste de germinação das sementes após inoculação artificial

De acordo com a análise estatística, os tratamentos compostos pelo meio 523, meio $523+$ manitol + Cff $\mathrm{SC}$ e meio $523+$ manitol diferiram estatisticamente entre si quanto à germinação das sementes de feijão. Sementes submetidas ao meio 523+manitol sem bactéria apresentaram maior percentagem de germinação em todos os tempos, comparadas àquelas submetidas ao meio $523+$ manitol $+C f f \mathrm{SC}$ e ao meio 523 sem restrição hídrica (Tabela 5). Com relação ao tratamento meio $523+$ manitol $+C f f$ SC, houve redução na percentagem de germinação, comparado ao meio 523+manitol e sem bactéria. A germinação das sementes diminuiu à medida que aumentou o tempo de permanência sobre o substrato, independente do tratamento. Porém, a redução da germinação não foi drástica, evidenciando, dessa forma, que a presença da referida bactéria não afetou a viabilidade da semente, possibilitando sua secagem e aproveitamento em estudos posteriores.

TABELA 5. Germinação média das sementes de feijão inoculadas artificialmente com $C f f$ SC (Feij-2928) em meio 523 + manitol -0,95 MPa.

\begin{tabular}{lccccc}
\hline Tratamentos & 24 horas & 48 horas & 72 horas & 96 horas & 120 horas \\
\hline Meio 523 & $42 \mathrm{c}^{1}$ & $40 \mathrm{c}$ & $36 \mathrm{c}$ & $32 \mathrm{c}$ & $28 \mathrm{c}$ \\
Meio 523+ manitol & $91 \mathrm{a}$ & $88 \mathrm{a}$ & $84 \mathrm{a}$ & $81 \mathrm{a}$ & $74 \mathrm{a}$ \\
Meio 523+ manitol + Cff & $81 \mathrm{~b}$ & $77 \mathrm{~b}$ & $73 \mathrm{~b}$ & $59 \mathrm{~b}$ & $51 \mathrm{~b}$ \\
\hline
\end{tabular}

${ }^{1}$ Médias seguidas pela mesma letra na coluna não diferem estatisticamente entre si, em $5 \%$ de probabilidade, pelo teste de Duncan. 
Segundo Vieira e Sartorato (1984), sementes de feijão portadoras de $X$. axonopodis pv. phaseoli, quando são colocadas para germinar, podem ter o meristema apical das plântulas destruído, acarretando-lhes a morte ou originando a plantas doentes, as quais produzirão poucas vagens, porém, com sementes viáveis. Além disso, sementes severamente atacadas por essa mesma bactéria apresentaram taxas reduzidas de germinação e produziram plântulas deformadas. Valarini e Menten (1991), utilizando sementes inoculadas artificialmente, constataram redução no poder germinativo das sementes, concordando com os resultados obtidos neste estudo com a bactéria $C f f$.

Portanto, a técnica de inoculação por contato direto da semente com o patógeno em meio de cultura com restrição hídrica, além de possibilitar a ocorrência de sintomas nas plântulas, é eficiente, prática e de fácil execução para estudos relacionados à transmissão de Cff pelas sementes, resistência de hospedeiros, controle e importância epidemiológica, visando obtenção de padrões de tolerância, assim como a determinação da sensibilidade de métodos de detecção desse patógeno em sementes.

\section{CONCLUSÕES}

O substrato meio 523+manitol, no potencial hídrico de $-0,95 \mathrm{MPa}$, no tempo de 48 horas é eficiente para a inoculação artificial de sementes de feijão com Curtobacterium flaccumfaciens pv. flaccumfaciens.

A técnica de inoculação por contato direto da semente com o patógeno em meio de cultura com restrição hídrica é eficiente em associar a bactéria com a semente, não comprometendo a sua qualidade fisiológica.

\section{AGRADECIMENTOS}

Os autores agradecem à Fundação de Apoio à Pesquisa de Minas Gerais - FAPEMIG, pelo financiamento do projeto (CAG 1603/06) e ao Conselho Nacional de Desenvolvimento Científico e Tecnológico - CNPq, pela concessão das bolsas de Produtividade e Doutorado.

\section{REFERÊNCIAS}

BARBOSA, J.F. Inoculação e detecção de Xanthomonas axonopodis pv. malvacearum em sementes de algodão (Gossypium hirsutum L.). 2007. 137f. Tese (Doutorado em Agronomia/Fitopatologia) - Universidade Federal de Lavras, 2007.
BAILLY, C.; BENAMAR, A.; CORBINEAU, F.; CÔME, D. Antioxidant systems in sunflower (Helianthus annus L.) seeds as affected by priming. Seed Science Research, v.10, n.1, p.35-42, 2000.

BRACCINI, A.L. Relação entre potencial hídrico, condicionamento osmótico e qualidade fisiológica de sementes de soja (Glycine max (L.) Merril). 1996. 135f. Tese (Doutorado em Agronomia/Fitotecnia) Universidade Federal de Viçosa, Viçosa, 1996.

BRADFORD, K.J. Manipulation of seed water relations via osmotic priming to improve germination under stress conditions. Hortscience, v.21, n.5, p.1105-1112, 1986.

BRASIL. Ministério da Agricultura e Reforma Agrária. Secretaria NacionaldeDefesaAgropecuária.Departamento Nacional de Produção Vegetal. Coordenação de Laboratório Vegetal. Regras para análise de sementes. Brasília, DF, 1992. 365p.

CAMPOS, I.S.; ASSUNÇÃO, M.V. Estresse salino e hídrico na germinação e vigor do arroz. Pesquisa Agropecuária Brasileira, v.25, n.6, p.857-862, 1990.

CARRARO, D.M. Variação e herança dos padrões eletroforéticos em orgãos e estágios de desenvolvimento em milho (Zea mays L.). 1990. 121f. Dissertação (Mestrado em Agronomia/Genética e Melhoramento de Plantas) - Escola Superior de Agricultura "Luiz de Queiroz”, Universidade de São Paulo, Piracicaba, 1990.

CARVALHO, J.C.B. Uso da restrição hídrica na inoculação de Colletotrichum lindemuthianum em sementes de feijoeiro (Phaseolus vulgaris L.). 1999. 98f. Dissertação (Mestrado em Agronomia/Fitopatologia) - Universidade Federal de Lavras, Lavras, 1999.

COUTINHO, W.M. Uso da restrição hídrica no controle da germinação de sementes de arroz (Oryza sativa $\mathrm{L}$.) e feijoeiro (Phaseolus vulgaris L.) em testes de sanidade. 2000. 78p. Dissertação (Mestrado em Agronomia/ Fitopatologia) - Universidade Federal de Lavras, Lavras, 2000.

FARIA, M.A.V.R.; VON PINHO, R.G.; VON PINHO, E.V.R.; GUIMARÃES, R.M. Marcadores moleculares da qualidade de fisiológica das sementes. Lavras: UFLA/FAEPE, 2003.

HALFELD-VIEIRA, B. de A.; SOUZA, R.M. Virulência de isolados de Xanthomonas axonopodis pv. phaseoli e sua variante fuscans. Ciência e Agrotecnologia, v.24, p.94-102, 2000.

KOBAYASTI, L. Inoculação, transmissão e detecção por Bio-PCR de Xanthomonas axonopodis pv. phaseoli 
em sementes de feijão. 2002. 125f. Tese (Doutorado em Agronomia/Fitopatologia) - Universidade Federal de Lavras, Lavas, MG.

KADO, C.I.; HESKETT, M.G. Selective media for isolation of Agrobacterium, Corynebacterium, Erwinia, Pseudomonas and Xanthomonas. Phytopathology, v.60, p.969-976, 1970.

MICHEL, B.E.; RADCLIFFE, D.A. A computer program relating solute potencial to solution composition for five solutes. Agronomy Journal, v.87, n.1, p.126-130, 1995.

ROMEIRO, R.S. Bactérias fitopatogênicas. 2.ed. Viçosa: Editor UFV, 2005. 417p.

SANTOS, C.M.R.; MENEZES, N.L.; VILLELA, F.A. Alterações fisiológicas e bioquímicas em sementes de feijão envelhecidas artificialmente. Revista Brasileira de Sementes, v.26, n.1, p.110-119, 2004.

SCHAAD, N.W.; JONES, J.B.; CHUN, W. Laboratory guide for identification of plant pathogenic bacteria. 3.ed. St. Paul: The American Phytopathology Society, 2001. 373p.

SOUZA, F.H.D.; MARCOS FILHO, J.; NOGUEIRA, M.C. Características físicas das sementes de Calopogonium mucunoides Desv. associadas à qualidade fisiológica e ao padrão de absorção de água. Revista Brasileira de Sementes, v.18, n.1, p.33-40, 1996.

SPINOLA, M.C.M.; CÍCERO, S.M.; MELO, M. Alterações bioquímicas e fisiológicas em sementes de milho causadas pelo envelhecimento acelerado. Scientia Agricola, v.57, n.2. p.263-270, 2000.

SUNG, J.M.; CHIU, C.C. Lipid peroxidation and peroxide-scavenging enzymes of naturally aged soybean seed. Plant Science, v.110, n.1, p.45-52, 1995.

VALARINI, P.J.; MENTEN, J.O.M. Inoculação artificial de sementes de feijão com Xanthomonas campestris pv. phaseoli e seu efeito sobre a qualidade sanitária e a germinação. Summa Phytopathologica, v.17, n.1, p.227231, 1991.

VIEIRA, E.S.N.; VON PINHO, E.V.R.; VIEIRA, M.G.G.C.; MANN, R.S. Similaridade genética entre cultivares de feijão do grupo carioca por meio de marcadores moleculares de proteínas e enzimas visando à certificação da pureza genética. Revista Brasileira de Sementes, v.23, n.2, p.35-42, 2001.

VIEIRA, R.F.; SARTORATO, A. Recomendações técnicas para produção de sementes de feijão (Phaseolus vulgaris) de alta qualidade. 2.ed. Goiânia: EMBRAPA/CNPAF, 1984. 46p. (EMBRAPA -CNPAF. Circular Técnica, 10). 